\title{
NOTE
}

\section{Nitrogen gas flux from sediments: insights from simulation modelling}

\author{
T. Henry Blackburn*
}

Department of Microbial Ecology, Department of Biological Sciences, Aarhus University, DK-8000 Aarhus C, Denmark

\begin{abstract}
Direct measurements of dinitrogen efflux from continental shelf sediments indicated that denitrification (mean $3.2 \mathrm{mmol} \mathrm{N} \mathrm{m}^{-2} \mathrm{~d}^{-1}$ ) was very important in nitrogen cycling. Most dinitrogen came from sediment-nitrate. All ammonium produced in these sediments was probably nitrified and then denitrified. In a closed incubation, the lineas production of dinitrogen, as oxygen decreased, was unexpected as was the low ratio of oxygen consumption to denitrification (3.6:1). Simulation modelling suggests the following explanation: Most carbon is oxidised anoxically, but nitrogen (ammonium) diffuses to the oxygen zone relatively deep in the sediment, where high rates of coupled nitrification-denitrification result. As oxygen decreases, the zones of nutrification and denitrification move upward. The nitrate initially present in the enclosed overlying water decreases, but due to the decreasing diffusional path to the zone of denitrification, its rate of denitrification remains constant. The concentration of nitrate from sediment nitrification increases in the overlying water, but due to the decreasing rates of sediment nitrification, its rate of denitrification is also constant.
\end{abstract}

KEY WORDS: Nitrification Denitrification - Model Diffusion - Nitrate A.mmonium

To construct a model which simulates a particular sediment, a variety of factors must be known: quantity of degradable organic matter, its $\mathrm{C} / \mathrm{N}$ ratio, its distribution in the sediment and the extent to which the reduced products of anoxic respiration are free to diffuse (Blackburn \& Blackburn 1993a, b, c, Blackburn et al. 1994). In addition, the rate constants for the oxidation of carbon by $\mathrm{O}_{2}, \mathrm{NO}_{3}{ }^{-}$and $\mathrm{SO}_{4}{ }^{2-}$, and for the oxidation of $\mathrm{NH}_{4}{ }^{+}$and $\mathrm{SH}^{-}$must be known. The values of the variables, outlined in the legend to Fig. 1, gave quite a close representation of the data for a continental shelf sediment (Devol 1991). Dinitrogen was produced at a linear rate (Fig. 1A). The total denitrification rate of $-3.7 \mathrm{mmol} \mathrm{N} \mathrm{m}^{-2} \mathrm{~d}^{-1}$ was similar to that reported (mean $3.2 \mathrm{mmol} \mathrm{N} \mathrm{m}^{-2} \mathrm{~d}^{-1}$ ). In the simulation (Fig. 1B),

•E-mail: henry@pop.bio.aau.dk there was a slight increase in $\mathrm{NO}_{3}{ }^{-}$concentration, compared to the actual slight decrease (mean $1.3 \mathrm{mmol} \mathrm{m}^{-2}$ $\mathrm{d}^{-1}$ ). Fine tuning of the nitrification and denitrification rates would correct this difference. During the time of $\mathrm{N}_{2}$ linear production (2 d), there was a fall in oxygen concentration from 200 to $20 \mu \mathrm{M}$. The initial rate of

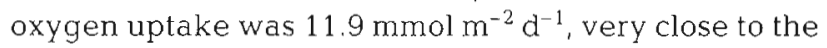
reported value $\left(11.4 \mathrm{mmol} \mathrm{m} \mathrm{m}^{-2} \mathrm{~d}^{-1}\right)$. As $\mathrm{O}_{2}$ decreased, accumulation of $\mathrm{NH}_{4}{ }^{+}$increased, due to the sediment becoming less oxidised (Fig. 1C). The model predicted a time-dependent decrease in the rate of nitrification from $-4.5 \mathrm{mmol} \mathrm{N} \mathrm{m}^{-2} \mathrm{~d}^{-1}$, but denitrification (Ds) of sediment $-\mathrm{NO}_{3}{ }^{-}$(NO3s) was relatively constant at -3 mmol $\mathrm{N} \mathrm{m}^{-2} \mathrm{~d}^{-1}$ (Fig. 1D). Denitrification (Dw) of $\mathrm{NO}_{3}^{-}$originally in the water $(\mathrm{NO} 3 \mathrm{w}$ ), was also relatively constant at $\sim 1 \mathrm{mmol} \mathrm{N} \mathrm{m}^{-2} \mathrm{~d}^{-1}$, even though NO3w decreased from 30 to $<10 \mu \mathrm{M}$.

The movement of the zone of denitrification closer to the sediment surface, as the depth of $\mathrm{O}_{2}$ penetration decreased with time (Fig. 2), can explain the apparent contradictions. The linear efflux of $\mathrm{N} 2 \mathrm{~s}$ ( $\mathrm{N}_{2}$ from NO3s) was due to the NO3s which accumulated in the water. The diffusional path for this Ds, back through the nitrification zone to the zone of denitrification, decreased with incubation time. This counteracted the decreased rate of nitrification and resulted in an almost constant, but slightly increasing, rate of Ds. Similarly, the decreased diffusional path for NO3w to the zone of denitrification counteracted the decreased concentration of NO3w and resulted in an almost constant rate for Dw.

It was suggested that most of the $\mathrm{NH}_{4}{ }^{+}$produced in the sediment $\left(\sim 2.5 \mathrm{mmol} \mathrm{N} \mathrm{m}^{-2} \mathrm{~d}^{-1}\right.$ ) (Christensen et al. 1987 ) would be nitrified and then denitrified (Devol 1991). This was unlikely, as nitrification initially exceeded Ds (Fig. 1D), and NO3s escaped to the overlying water. It is only in the situation where this NO3s is trapped in water overlying the sediment surface that Ds 

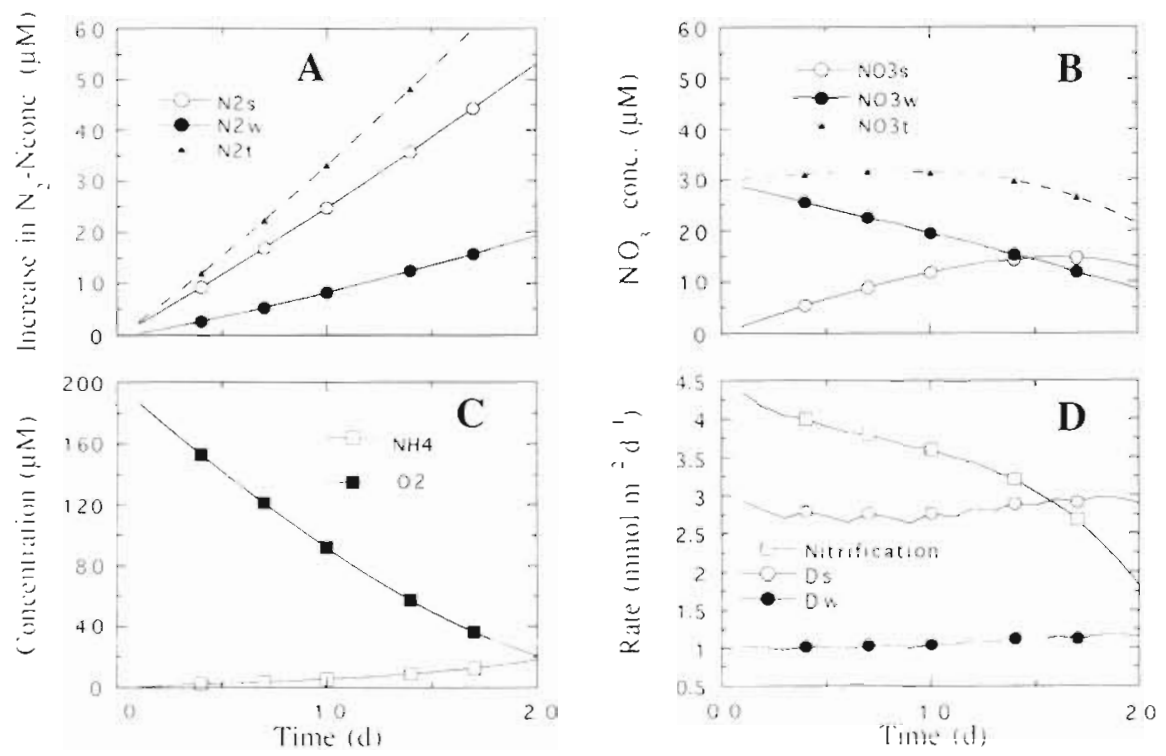

Fig. 1. Predicted time-dependent changes in the concentrations in the enclosed overlying water of dinitrogen (N2s) derived from sediment-nitrate (NO3s), in dinitrogen (N2w) derived from nitrate initially in the overlying water (NO3w), in total dinitrogen ( $\mathrm{N} 2 \mathrm{t}$ ) derived from total nitrate ( $\mathrm{NO} 3 \mathrm{t}$ ), in ammonium (NH4), and in oxygen (O2). Also shown are changes in the integrated rates of sediment nitrification, and denitrification of NO3s (Ds) and of NO3w (Dw). Predictions were derived from a reaction-diffusion model in Cellmatic (Blackburn \& Blackburn 1993a). In the present model, the upper $1 \mathrm{~cm}$ of sediment was represented by 14 cells of $0.2 \mathrm{~mm}$ and 6 cells of $1.0 \mathrm{~mm}$, overlaid by water ( 1 cell of $10 \mathrm{~cm}$ and 2 cells of $0.2 \mathrm{~mm}$ ). Half the dissolved organic carbon $\left(22.5 \mathrm{mmol} \mathrm{m} \mathrm{m}^{-2} \mathrm{~d}^{-1}\right)$ was oxidised below $1 \mathrm{~cm}$, and half was distributed evenly in the upper $1 \mathrm{~cm}$ stratum. Ammonium (4.5 mmol $\mathrm{m}^{-2} \mathrm{~d}^{-1}$ ) was produced at $\mathrm{l} / 10$ the rate of carbon oxidation. Reduced products of anoxic respiration, e.g. iron sulphides, were not allowed to diffuse. The first order rate constants for nitrification and denitrification were 200 and $500 \mathrm{~d}^{-1}$, respectively. Otherwise, constants were as previously reported (Blackburn \& Blackburn 1993a). At time zero, the sediment core with $10 \mathrm{~cm}$ of overlying water was sealed

can equal nitrification. Simulations in which NO3s was not allowed to accumulate in the increasingly $\mathrm{O}_{2}$-deficient overlying water indicated that there was a very rapid fall in Ds, in parallel with the fall in nitrification

The non-diffusion of sulphide was a very important factor. When sulphide was allowed to diffuse, it reacted with $\mathrm{O}_{2}$, reducing $\mathrm{O}_{2}$ penetration and raising the zone of nitrification closer to the sediment surface. This reduced the rate of nitrification, but increased the proportion of NO3s escaping to the overlying water (data not shown). This has been discussed elsewhere (Blackburn \& Blackburn 1993b) and also results in observed low rates of $\mathrm{O}_{2}$ uptake (Canfield et al. 1993). In this simulation, although the rate of $\mathrm{O}_{2}$ uptake was $11.9 \mathrm{mmol} \mathrm{m}^{-2} \mathrm{~d}^{-1}$, the rate of carbon oxidation was

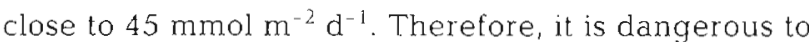
equate $\mathrm{O}_{2}$ uptake with carbon oxidation, and it is likely that in the continental shelf sediments, most carbon oxidation is not $\mathrm{O}_{2}$-dependent. This could account for the high ratio of denitrification/ $\mathrm{O}_{2}$ uptake, in the original data $(1: 3.6)$ and in the simulation $(1: 3.2)$.

The irregularities in the sediment-based rates of nitrification and denitrification (Fig. 1D) may be due to the fact that these rates are influenced by multiple factors: $\mathrm{O}_{2}$ concentration, substrate concentration and

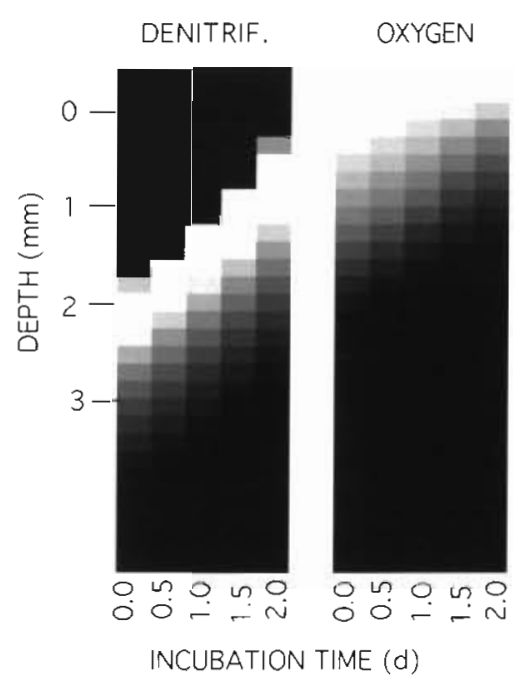

Fig. 2. Predicted time-dependent changes in the vertical distributions of sediment denitrifyıng activity and in pore water oxygen concentrations. Model parameters are described in

Fig. 1. Light areas indicate high activity or concentration 
varying diffusional path lengths. Therefore, it is not surprising that some unevenness is observed. These irregularities in the rates are not reflected in concentration changes in the overlying water, probably due to the larger volume of this overlying water, which dampens the oscillations.

In conclusion, the tight coupling between nitrification and denitrification can be attributed to the deep location of the zone of nitrification. The linear production of dinitrogen, despite oxygen depletion, can be explained by the accumulation of sediment-derived nitrate in the enclosed overlying water and to the movement of the zone of denitrification closer to the sediment surface.

This paper describes the novel employment of simulation analysis to explain apparant anomalies in experimental data. The confirmation that the data are consistent suggests that the high values for denitrification (Devol 1991) are reliable. This has important implications for global nitrogen budgets.

Responsible Subject Editor: F. Thingstad, Bergen, Norway

\section{LITERATURE CITED}

Blackburn ND, Blackburn TH (1993a) A reaction diffusion model of $\mathrm{C}-\mathrm{N}-\mathrm{S}-\mathrm{O}$ species in a stratified sediment. FEMS Microbiol Ecol 102:207-215

Blackburn TH, Blackburn ND (1993b) Coupling of cycles and global significance of sediment diagenesis. Mar Geol 113 $101-110$

Blackburn TH, Blackburn ND (1993c) Rates of microbial processes in sediments. Phil Trans R Soc Lond Ser A 344: $49-58$

Blackburn TH, Blackburn ND, Jensen K, Risgaard-Petersen N (1994) Simulation model of the coupling between nitrification and denitrification in a freshwater sediment. Appl Environ Microbiol 60:3089-3095

Canfield DE, Jorgensen BB, Fossing H, Glud R, Gundersen $J$, Ramsing NB, Thamdrup B, Hansen JW, Nielsen LP, Hall POJ (1993) Pathways of organic carbon oxidation in three continental margin sediments. Mar Geol 113:27-40

Christensen JP, Smethie WM, Devol AH (1987) Benthic nutrient regeneration and denitrification on the Washington continental shelf. Deep Sea Res 34:1027-1047

Devol AH (1991) Direct measurement of nitrogen gas fluxes from continental shelf sediments. Nature 349:319-321

Manuscript first received: September 22, 1995

Revised version accepted: February 28, 1996 